\title{
Literature Learning in the Malaysian ESL Classroom: A UiTM Experience
}

\author{
Chittra Muthusamy \\ Universiti Teknologi Mara, Malaysia, \\ Academy of Language Studies, Terengganu. \\ Email: chitt911@tganu.uitm.edu.my
}

Rasaya Marimuthu and Angelina Subrayan @ Michael

Universiti Teknologi Mara, Malaysia,

Academy of Language Studies, Pulau Pinang.

Email: rasay386@p.pinang.uitm.edu.my and angiesubrayan@yahoo.com

\author{
Siti Norliana Binti Ghazali and Jeyamahla Veeravagu \\ Universiti Teknologi Mara, Malaysia, \\ Academy of Language Studies, Terengganu. \\ Email: liana265@tganu.uitm.edu.my_and jeyamahla@tganu.uitm.edu.my
}

\begin{abstract}
This paper discusses a study which explored a method of integrating literature in English Language proficiency courses at University technology Mara, (UiTM) Terengganu, Malaysia. A quasi-experimental study was conducted on two intact groups; the control and experimental groups respectively. Both groups underwent a eight week experiment whereby one short story, The Burden of Sin by S. Karthigesu was taught to the control group using the routine reading and comprehension teaching approach while the experimental group was taught using the reader response approach adapting Ibsen's The I Model text exploration and literary devices. Descriptive and inferential statistical analyses were conducted on the data using two nonparametric tests: the Wilcoxon Signed Rank test to determine the significance difference between the pretest and posttest scores; and the Mann-Whitney $U$ test to determine the significant difference between the scores of the experimental and control groups. The results proved to be substantially significant; that by integrating literature in the language curricula, students can learn the four skills - listening, speaking, reading and writing- more effectively because of the literary promoting cultural, higher-order thinking and motivational benefits that fortify it.
\end{abstract}

Index Terms - English Language teaching, essay writing, experimental study, literature based language instruction

\section{INTRODUCTION}

The teaching of English proficiency courses known as BEL 120 and BEL 260 in Universiti Teknologi Mara (UiTM) in Malaysia specifies the basic skills of listening, speaking, reading and writing. The fundamental goal is to prepare students to engage in fluent and effective communication as well as to analyze information focusing mainly on composition, grammatical structures and matters of style and convention. Through experience in teaching and evaluating the students' language learning performance, the researchers found that as learners of ESL, UiTM students face problems in the writing skill compared to other basic language learning skills. However, students cannot be entirely blamed for poor performances as writing has for a long time been claimed as a very difficult skill to acquire and dreaded by ESL students (Gupta, 1998). The notion of success in learning English writing is associated with selfexpressions, the flow of ideas, outsider expectations, growing confidence and enjoyment of L2 academic writing. The most common problem that confronts teachers of a writing class does not lie so much on what to ask the students to write about; the difficulty is more to motivate the students to write interesting and effective materials. As a result writing for writing sake has become a drag, and produces shallow and boring output. In most BEL proficiency classes some of these students sorely lacking in practice and stimulus for imagination and creativity, do not have much to say. To a certain degree their writing in general reads dull and dry, their stories are mere displays of boring chronological events, having no life, content and some direly lacking in proficiency. This study was conducted as one of varied methods to improve UiTM students' level of ESL proficiency specifically in their writing skills; by employing a literature based language learning method. The paper seeks to explain that the teaching of literature in language courses is effective and enables students to produce better pieces of essays in terms of content, creativity and proficiency.

\section{LITERATURE REVIEW}




\section{A. Literature in the Malaysian Context}

In order to prove that literature has a significant role in language studies, it is pertinent to look at the development of literature teaching in English classes and the activities undertaken by the Malaysian Education Ministry. Literature in English at the upper secondary level is offered as an elective paper mostly studied for examination purposes till today. In the past the study was limited to a few urban students from elite schools, with exceptional mastery of the language (Rosli, 1995). In the Ministry's initial effort to increase the student's exposure to English, the introduction of English Language Reading Programme (ELRP) was carried out in the 1980's. Complementing this undertaking is the Class Reader Programme (CRP) introduced to all government schools in the 1990's. One of the primary aims of this programme is to inculcate the elements of literature into language teaching. Currently, content-based language teaching is introduced in Malaysian Secondary schools which commenced since 2000. In this programme, twenty percent of class time in a week is allocated to the teaching of English through literature. Initially it was introduced to upper secondary students of forms 4 and 5 and later on introduced to all levels of secondary school. Currently primary school students in standard 4 and 5 are also learning literature via their English classes. This time around the government felt that literature could help to increase the standard of English, which was then declining, and also to cultivate a passion for reading and encourage creative writing. More recently with the initiation of MELTA (Malaysian English Language Teaching Association) and in its effort to encourage more students to take up Literature in English as an elective course in the SPM (high school) examination, the ministry is on the verge of revamping its literature syllabus to give it a more teen friendly outlook by "marrying ICT with literature" hence hoping to make it more appealing and interesting to techno savvy $21^{\text {st }}$ century teens who to a certain degree find literature somehow boring if not a time consuming subject (Hariati Azizan, 2007, p. E2).

\section{B. Benefits of Using Literature in the Malaysian ESL Classroom}

The main argument for the use of literature is that it encourages the awareness among learners on how the language works. When learners are taught effectively, literature enhances learners' knowledge of syntax, morphology, semantics and phonetics. Widdowson (1975) has stressed that the study of literature is essentially a study of language and both are inseparable as they create "a sharp awareness of the communicate resources of the language being learnt" (p, 81). This fact has been also stressed by others who state that the teaching of literature provides the student with abundance of examples of the subtle and complex uses of idioms, literary knowledge and vocabulary enrichment. Apart from this, literature can also enhance listening, speaking and reading skills according to Hill (1989). It is through literature that learners can be introduced to what Gwin (1990, p. 10) calls the "subtle elements that go into the creation of what is called good writing'.

L2 researchers and practitioners who seek communication as the primary goal of instruction also encourage the use of literature. Sage (1987) argues that literature represents various uses of the language, conventional and literary, displays a broader range of communication strategies than any other single language teaching component, and extends linguistic knowledge on the levels of usage and use. When students read literature, they learn the target language in a whole context rather than memorizing words and rules. This way of getting knowledge about language resembles the subconscious process of language acquisition proposed by Krashen \& Terrell (1991). Unlike formal learning of vocabulary and language structure in the classroom, literature provides an informal but supportive environment for students to naturally develop their linguistic system.

While some instructors still believe that teaching ESL encompasses focusing on linguistic benefits solely, so eventually their students will communicate in the target language, others who have integrated literature in the curricula have realized that literature adds a new dimension to the teaching of ESL. Literature represents human experience. It is a mirror of life. A study of literature often involves themes, characters and events that address complex situations and dilemmas which engage students intellectually, emotionally and linguistically. As literature introduces a varied of materials such as poems, plays, novels and other genres, it makes learning and teaching more interesting and fun. In turn it also introduces a change in activity and is certainly a different way of engaging the students. Clearly, the use of literature has been acknowledged as conducive to academic, intellectual, cultural and linguistic learning (Sage, 1987; Spack, 1985).

Moreover in a literature integrated language instruction, learners are exposed to the spiritual, aesthetic and moral values that are inherent in the nation's social system as national culture is often reflected in its literature (Spack, 1985). Hence literature can be a pedagogic tool to execute many government policies in Malaysia such as the National Unity and Integration Plan 2006 and National Education Policy 2006 - 2010 in which one of its objectives is to produce "well - rounded students". As a multicultural country, Malaysia like many other countries in the world at present is not spared from the onslaught of cross-cultural conflicts and interests. The teaching of literature can help cultivate cultural understanding and awareness as '1Malaysia', a concept mooted by Datuk Seri Najib Tun Abdul Razak, the Prime Minister, as a vision and concept to unite all Malaysians of different beliefs, colour and race. Ultimately by integrating literature in the language curricula, students can learn the four skills - listening, speaking, reading and writing- more effectively because of the literary, cultural, higher-order thinking and motivational benefits that are discernible along the way. 


\section{METHODOLOGY}

A quasi-experimental design was employed for this study because subjects were not randomly assigned to treatments. More specifically, the design employed was a non-equivalent control group design with pretest-posttest. The quasiexperimental design was conducted for the two groups: the control and experimental groups.

\section{A. Research Hypotheses}

Hypothesis One $\left(\mathrm{Ho}^{\mathrm{I})}\right.$ :

$H \mathrm{H}^{I a}$ : There is no significant difference between the pretest and posttest performance of the experimental group in the language proficiency aspect.

$H o^{l b}$ : There is no significant difference between the experimental group and the control group in the posttest performance for the language proficiency aspect.

Hypothesis Two $\left(\mathrm{Ho}^{2)}\right.$ :

$\mathrm{Ho}^{2 a}$ : There is no significant difference between the pretest and posttest number of occurrences of sentence structures for the experimental group.

$H o^{2 b}$ : There is no significant difference between the experimental group and the control group in the posttest number of occurrences of sentence structures.

\section{B. Sample}

A total of 60 students $(\mathrm{N}=60)$ from two classes participated in the study. The experimental group (N=30) belonged to the Diploma in Food Science Management (DFSM) programme and the control group (N=30) belonged to the Diploma in Culinary Art (DCA) programme. As mentioned earlier, since this is a quasi-experimental study specifically nonequivalent control-group design, the samples were not randomized.

\section{Research Instrument and Procedure}

A short story by a Malaysian writer titled The Burden of Sin with the length of 2012 words and 63 paragraphs was chosen. It was written by R. Karthigesu. A short story was chosen to represent literature as a whole. However in the ESL context, Reid (1993) claims that full-length novels or fiction may not provide input as comprehensible as short stories which have become model examples of language style and length for production. Briefly, the story is about how an Indian father rejects an inter-racial love relationship between his son and his Malay neighbour's daughter and lives to regret it. He returns to the village after twenty five years to "wash the burden of his sin", an allusion to Hindu ritual cleansing. All the students read the story in week one. Before the pretest was conducted, a pilot test was conducted on 25 students from the same population involving another intact group, Diploma in Islamic Banking (DIB) to test whether the expected answers can be gauged from students answering the essay questions. It was an eight week experimental study. The pretest questions in essay form were handed out to the students where students had to answer based on their comprehension of the short story. This was done in the first week. Later the experimental group underwent a six week intervention programme where they were taught text exploration using Ibsen's (1990), the I-model, a reader response approach, along with lectures on literary terms and devices. Meanwhile the control group underwent a normal reading and comprehension class activity. Subsequently in the eighth week, a posttest was administered, again in essay form, on both groups. The questions were similar in content as the pretest questions but different in sentence structures.

\section{Treatment / Intervention/Instructional Procedures}

This study employed the reader-response technique to engage the students' interest in literature. The dependent variable or the experimental group was taught using a modified version of The I-Model by Ibsen (1990). According to Ibsen, this method of text exploration will acknowledge the readers' own terms of response to the literary text as well as develop proficiency, communicative, creative and cultural competences in the readers. The following was carried out with the experimental group.

\section{E. Stages of Text Exploration Adapted from Ibsen's (1990) the I-model.}

\section{Involvement Stage}

This is divided into the impetus stage and the input stage.

a. The Impetus stage contains pre-reading activities. It functions as the initiation stage for reading. The instructor, here, provided questions or cues pertaining to the reading text. For example, before reading Burden of Sin, the instructor elicited responses from students on their perception of inter-racial love and marriage.

b. During the Input stage, the language (literary devices) and the content of the reading text is focused. The students were provided with copies of notes on literary elements of short stories and literary devices. These were thoroughly elaborated and discussed during the treatment period. Then students were asked to list down the literary devices such as similes, symbols, metaphors that they can identify in the short story.

2 Interaction Stage

This stage is divided into two parts; the Identification Stage and the Incubation Stage. During these stages, the reader and the story interact and there is active reading and negotiation of meaning. 
a. The identification Stage requires the readers to assume the role of certain characters in the story. For example students acted out certain scenes out of the story such as Sulaiman's anger when he found out that his daughter loved Devan, Hasnah's and Devan's tearful parting when Velu decided to leave the village, Velu's return to the village after 25 years and meeting again with his friend, Sulaiman and etc. By assuming the characters in the story, the readers will be able to foster greater understanding of the story as they will be able to gauge wider perspectives of the subject matter.

b. The Incubation Stage is the time for reflection and after thought. To further elicit, a reader response handout was distributed.

3 Interpretation Stage

This stage focuses on the integration of the text/short story. The input and knowledge obtained from the story together with the learning of basic tenets of literature and literary devices were assimilated and condensed by the students to form a holistic understanding of the text.

\section{F. Measurement}

Steps employed in the content analysis procedure to test the hypotheses:

i. To test overall language proficiency in the essay, an external rater/judge was chosen and she rated using a normreferenced measure, an achievement test. Students were graded between $1-10$ marks in a holistic marking procedure.

ii. To test content and elaboration, the external rater/judge identified the number of sentence structures in both pretest and posttest, counted and recorded them.

\section{G. Data Analysis Procedure}

First a content analysis was performed on the students' essays (pre and post tests results).Next, a descriptive analysis on the individual scores for the pretest and posttest was conducted using SPSS version 10. This procedure was later followed by an inferential analysis. Since the sampling was not randomized, we used non-parametric tests to elicit this information, namely the Wilcoxon Signed-Rank test and the Mann-Whitney U test. The Wilcoxon Signed Rank test was used to determine whether the distribution of scores in (two related samples) the pretest and posttest differed significantly; whilst the Mann-Whitney U test was used to determine whether the distribution of scores of the two independent samples (experimental and control group) differed significantly from each other.

\section{RESULTS AND DISCUSSION}

Through this study the researchers have positively identified that the integration of literature in English language proficiency courses to a certain level does contribute towards an improved performance among the subjects especially in the experimental group.

Descriptive statistics involving the subjects of the experimental group is $(\mathrm{N}=30)$. Notably, the mean rank (scores) for the language proficiency (pretest $=4.1$, posttest $=6.8$ ) and occurrence of the number of sentence structures (pretest $=$ 9.4 , posttest $=18.4)$ whereas descriptive statistics involving the subjects of the control group is $(\mathrm{N}=30)$. Notably, the mean rank (scores) for the language proficiency is (pretest $=4.4$, posttest $=5.2$ ) and occurrence of the number of sentence structures is (pretest $=9.6$, posttest $=12.8$ ). The result evinces that the experimental group has higher scores compared to the control group. 
TABLE 1

WILCOXON SIGNED RANKS TEST FOR RELATED MEASURES FOR LANGUAGE PROFICIENCY

Ranks ${ }^{d}$

\begin{tabular}{|c|c|c|c|c|c|}
\hline & & $\mathbf{N}$ & Mean & Rank & $\begin{array}{l}\text { Sum o1 } \\
\text { Ranks }\end{array}$ \\
\hline \multirow{4}{*}{$\begin{array}{l}\text { Language Proficiency - } \\
\text { Posttest Score - Language } \\
\text { Proficiency - P retest Score }\end{array}$} & Negative Ranks & $\mathrm{O}^{\mathrm{a}}$ & & .00 &. $\mathrm{OCl}$ \\
\hline & Positive Ranks & $30^{b}$ & & 15.50 & 465.00 \\
\hline & Ties & $\mathrm{O}^{\mathrm{C}}$ & & & \\
\hline & Total & 30 & & & \\
\hline
\end{tabular}

a. Language Proficiency - Posttest Score < Language Proficiency Pretest Score

b. Language Proficiency - Posttest Score > Language Proficiency Pretest Score

C. Language Proficiency - Pretest Score = Language Proficiency - Postte Score

d. Group Orientation = Experimental Group

Test Statistics,c

\begin{tabular}{lr}
\hline \hline & $\begin{array}{c}\text { Language Proficiency - Posttest Score - } \\
\text { Language Proficiency - Pretest Score }\end{array}$ \\
\hline$Z$ & $-4.853^{a}$ \\
Asymp. Sig. (2-tailed) & .000 \\
\hline \hline
\end{tabular}

a. Based on negative ranks.

b. Wilcoxon Signed Ranks Test

c. Group Orientation = Experimental Group

TABLE 2

MANN-WHITNEY U TEST FOR INDEPENDENT SAMPLES FOR LANGUAGE PROFICIENCY

Ranks

\begin{tabular}{llcrc}
\hline \hline & Group Orientation & N & Mean Rank & $\begin{array}{c}\text { Sum of } \\
\text { Ranks }\end{array}$ \\
\hline Language Proficiency & Experimental Group & 30 & 28.13 & 844.00 \\
- Pretest Score & Control Group & 30 & 32.87 & 986.00 \\
& Total & 60 & & \\
\hline Language Proficiency & Experimental Group & 30 & 40.00 & 1200.00 \\
- Posttest Score & Control Group & 30 & 21.00 & 630.00 \\
& Total & 60 & & \\
\hline \hline
\end{tabular}

Test Statistics

\begin{tabular}{lcc}
\hline \hline & $\begin{array}{c}\text { Language } \\
\text { Proficiency - } \\
\text { Pretest } \\
\text { Score }\end{array}$ & $\begin{array}{c}\text { Language } \\
\text { Proficiency - } \\
\text { Posttest } \\
\text { Score }\end{array}$ \\
\hline Mann-Whitney U & 379.000 & 165.000 \\
Wilcoxon W & 844.000 & 630.000 \\
Z & -1.090 & -4.297 \\
Asymp. Sig. (2-tailed) & .276 & .000 \\
\hline \hline
\end{tabular}

a. Grouping Variable: Group Orientation

The Wilcoxon Signed Ranks Test for related measures in pretest and posttest for the experimental group of: $z=-$ 4.853, $N=30, p<0.05$ as shown in table 1 indicates that there is a significant difference between the mean ranks (scores) in language proficiency after treatment phase. Therefore, the null hypothesis $\left(\mathrm{Ho}^{l a}\right)$ that says there is no difference between the pretest and posttest performance of the experimental group ought to be rejected. In other words, there is a marked improvement in the performance of the students in the aspect of language proficiency after going through the treatment phase. Table 2 illustrates the Mann-Whitney $U$ test for independent samples which yielded the following results: $z=-4.297, N=30, p<0.05$ in the posttest. It can be deduced that there is a significant difference between the mean ranks (scores) of the experimental and the control groups in the posttest. On the other hand, the 
pretest result shows the mean ranks (scores) difference between the two groups was not significant $(z=-1.090, N=30$, $p>0.05)$, suggesting that the subjects of both the control and experimental groups belong to the same level in terms of their language proficiency before the treatment phase. Therefore, the null hypothesis $\left(H o^{l b}\right)$ that says there is no difference between the experimental group and the control group in the posttest performance ought to be rejected. In other words, the subjects of the experimental group had performed significantly better in the language proficiency aspect, in the posttest after undergoing the intervention stage, as compared to the subjects of the control group who did not undergo any treatment. The experimental group scored better in language proficiency in the posttest by extracting sentence structures from the short story to substantiate their stance. For example Nurul Ezalin of the experimental group writes 'The author gives a realistic picture of the Malay life and practices'. There are some figurative language used in the story, for example, "The latex had dried to a golden yellow at the place where it had been tapped" explains an imagery of the kampong...', strengthens Widdowson's (1975) claim that language and literature cannot be separated as they are a 'whole'. When students read literature, they learn the target language in a whole context rather than memorizing words and grammar rules. The whole language approach used to teach literature uses real literature and writing in the context of meaningful, functional and cooperative experiences in order to develop in students' motivation and interests in the process of learning in what Krashen \& Terrell (1991) calls as the subconscious process of language acquisition.

TABLE 3

WiLCOXON SIGNED RANKS TEST FOR RELATED MEASURES FOR THE NUMBER OF SENTENCE $\quad$ STRUCTURE OCCURRENCES

Ranks ${ }^{d}$

\begin{tabular}{|c|c|c|c|c|}
\hline & & $\mathrm{N}$ & Mean Rank & $\begin{array}{l}\text { Sum of } \\
\text { Ranks }\end{array}$ \\
\hline \multirow{4}{*}{$\begin{array}{l}\text { Number of Sentence } \\
\text { Structures - Posttest Score } \\
\text { - Number of Sentence } \\
\text { Structures - Pretest Score }\end{array}$} & Negative Ranks & $0^{a}$ & .00 & .00 \\
\hline & Positive Ranks & $30^{b}$ & 15.50 & 465.00 \\
\hline & Ties & $0^{\mathrm{C}}$ & & \\
\hline & Total & 30 & & \\
\hline
\end{tabular}

a. Number of Sentence Structures - Posttest Score $<$ Number of Sentence Structures - Pretest Score

b. Number of Sentence Structures - Posttest Score > Number of Sentence Structures - Pretest Score

c. Number of Sentence Structures - Pretest Score = Number of Sentence Structures - Posttest Score

d. Group Orientation = Experimental Group

Test Statistics,c

\begin{tabular}{lcc}
\hline \hline & $\begin{array}{l}\text { Jumber of Sentence Structures - Posttest Score - Numbe } \\
\text { of Sentence Structures - Pretest Score }\end{array}$ \\
\hline$Z$ & $-4.802^{\mathrm{a}}$ \\
Asymp. Sig. (2-tailed) & .000 \\
\hline \hline
\end{tabular}
a. Based on negative ranks.
b. Wilcoxon Signed Ranks Test
c. Group Orientation = Experimental Group 
TABLE 4

MANN-WHITNEY U TEST FOR INDEPENDENT SAMPLES FOR THE NUMBER OF SENTENCE STRUCTURE OCCURRENCES

Ranks

\begin{tabular}{llrrr}
\hline \hline & Group Orientation & N & Mean Rank & $\begin{array}{c}\text { Sum of } \\
\text { Ranks }\end{array}$ \\
\hline Number of Sentence & Experimental Group & 30 & 29.68 & 890.50 \\
Structures - Pretest Score & Control Group & 30 & 31.32 & 939.50 \\
& Total & 60 & & \\
& Experimental Group & 30 & 43.22 & 1296.50 \\
& Number of Sentence & 30 & 17.78 & 533.50 \\
Structures - Posttest Scort & Control Group & 60 & & \\
& Total & & & \\
&
\end{tabular}

Test Statistics

\begin{tabular}{lcc}
\hline \hline & $\begin{array}{c}\text { Number of } \\
\text { Sentence } \\
\text { Structures - } \\
\text { Pretest } \\
\text { Score }\end{array}$ & $\begin{array}{c}\text { Number of } \\
\text { Sentence } \\
\text { Structures - } \\
\text { Posttest } \\
\text { Score }\end{array}$ \\
\hline Mann-Whitney U & 425.500 & 68.500 \\
Wilcoxon W & 890.500 & 533.500 \\
Z & -.366 & -5.664 \\
Asymp. Sig. (2-tailed) & .714 & .000 \\
\hline \hline
\end{tabular}

a. Grouping Variable: Group Orientation

The Wilcoxon Signed Ranks Test for related measures in table 3 had yielded the following results: $z=-4.802, N=30$, $p<0.05$. It can be deduced that there is a significant difference between the mean ranks (scores) of the pretest and posttest as attained by the subjects of the experimental group. Therefore, the null hypothesis $\left(\mathrm{Ho}^{2 a}\right)$ that says there is no difference between the pretest and posttest performance of the experimental group ought to be rejected. In other words, there is an increase in the number of sentence structures among the students after going through the treatment phase. Table 4 yields results of the Mann-Whitney $\mathrm{U}$ test for independent samples; $z=-5.664, N=30, p<0.05$ in the posttest. It can be deduced that there is a significant difference between the mean ranks (scores) of the experimental and the control groups in the posttest. On the other hand, the pretest result shows the mean ranks (scores) difference between the two groups was not significant $(z=-0.366, N=30, p>0.05)$, suggesting that the subjects of both the control and experimental groups belong to the same level in terms of the language structure occurrences before the treatment phase. Therefore, the null hypothesis $\left(\mathrm{Ho}^{2 b}\right)$ that says there is no difference between the experimental group and the control group in the posttest performance ought to be rejected. In other words, the subjects of the experimental group had managed to produce significantly more sentence structures in the post test after undergoing the intervention stage, as compared to the subjects of the control group who did not undergo any treatment.

There is a significant difference between the mean ranks (scores) of the experimental and the control groups in the posttest. The experimental group did elaborate their writing content substantially. Gwin (1990) suggests that by focusing on text structures literature enhances students' comprehension and improves their recall of information presented in the text. By discussing the issues presented in the short story, subjects from the experimental group conveyed their thought through written language while commenting on the characters' in the story and their opinion of the characters' actions. To do this they need back up from the story and more often than not these extracted sentence structures from the story which not only substantiated their opinions but ended up as elaborated content in the form of cited examples.

Therefore not only do they write in correct structures, they use the correct form of language and this method in cognitive term means that they are being creative (Erkaya, 2005). Consequently this results in better pieces of essays in terms of language proficiency. Quite interestingly even the control group scored a (pretest $=9.6$, posttest $=12.8$ ) mean rank (scores) for occurrence of the number of sentence structures in which this is an indication that these subjects too have made references to the story to authenticate their opinions.

\section{CONCLUSION}

The teaching of literature is compatible with a focus on the development of English fluency precisely because by discussing the issues presented in literature; for example short stories, students can convey their thoughts through language: promote higher level thinking skills and use language authentically. As have been discussed, literature does indeed help students to expand their linguistic and cognitive skills, cultural knowledge and sensitivity. In terms of 
classroom practice and instruction design, this study has the following implications. Literature, when selected carefully, can be a valuable resource for integrative ESL learning. Since stories tend to invoke our imagination and desire for creating, composition classes can be conducted better than the drab routines of students-write-and-teacher-correct routine by injecting the elements of interest and fun. Students in the experimental group read out loud the story and role-played the parts. They also shared their reflections on what they had read during discussions, and oftentimes revealed themselves when they found the stories related to their personal experiences. They were able to display some level of critical and creative ability in writing and these were reflected in their essays. Since the goal of ESL teaching is to help students to communicate fluently in the target language, instructors must diversify their focus of attention to not only include linguistic aspects but also other benefits such as creativity and cultural aspects.

\section{REFERENCES}

[1] Erkaya, O. R. (2005). Benefits of using short stories in the EFL Context. Asian EFL Journal, 8, 1-13.

[2] Gupta, R. (1998). Writing with a different tool. Computers and language learning. Singapore: SEAMEO.

[3] Gwin, T. (1990). Language skills through literature. Forum. XXVII (3) 10-13.

[4] Hariati Azizan. (2007). Bridging cultures. The Sunday Star, March 11.

[5] Hill, J.(1989). Using literature in language teaching. London: Macmillan Publishers Ltd.

[6] Ibsen, E. B. (1990). The double role of fiction in foreign language learning: Towards a creative Methodology. English Teaching Forum, 28 (3), 27.

[7] Karthigesu, S. The Burden of Sin. B.Ed (TESL). Comparative Literature Syllabus. Education Faculty, UiTM Section 17, Shah Alam. (Unpublished).

[8] Krashen, S. D. \& Terrell, T. D. (1991). The natural approach: Language acquisition in the classroom. New York: Prentice Hall International.

[9] Reid, J. (1993). Historical perspectives on reading in the ESL classroom. In J.G. Carson, \& I. Leki (Eds.), Reading in the composition classroom: Second language perspectives. 33-60.

[10] Rosli Talif. (1995) Teaching literature in ESL: The Malaysian context. Serdang: UPM Publisher.

[11] Sage, H. (1987). Incorporating literature into ESL instruction. Englewood Cliffs, NJ: Prentice-Hall.

[12] Spack, Ruth. (1985). Literature, reading and writing, and ESL. Bridging the gaps. TESOL Quarterly 19(4): 703 - 725.

[13] Widdowson, H.G. (1975). Stylistics and the teaching of literature. Essex: Longman.

Chittra Muthusamy is currently a lecturer with the Academy of Language Studies, Universiti Teknologi Mara, Terengganu. Her areas of interest are language, literature and literary and literacy in ESL as well as nineteenth century British and American Romanticism.

Rasaya Marimuthu is currently a lecturer with the Academy of Language Studies, Universiti Teknologi Mara, Pulau Pinang. His areas of interest are mind-mapping, CALL as well as language and linguistics.

Angelina Subrayan @ Michael is currently a lecturer with the Academy of Language Studies, Universiti Teknologi Mara Malaysia. Her areas of interest are language, literature and literary as well as gender studies.

Siti Norliana Ghazali is currently a lecturer with the Academy of Language Studies, Universiti Teknologi Mara Terengganu. She specializes in the areas of language and literature and has published in these areas.

Jeyamahla Veeravagu is currently a lecturer with the Academy of Language Studies, Universiti Teknologi Mara Terengganu. Her areas of interest are reading and writing. 